\title{
A QUESTÃO DO SENTIDO EM KANT SEGUNDO ERIC WEIL
}

\author{
Evanildo COSTESKI ${ }^{1}$
}

- RESUMO: Este artigo quer mostrar que Kant descobriu, segundo Eric Weil, o problema do sentido. Entretanto, Eric Weil observa que Kant não encontrou uma linguagem apropriada para falar do sentido. A linguagem de Kant era ainda uma linguagem ontológica. Malgrado isso, Kant conseguiu fechar, na terceira Crítica, o abismo que separava natureza e liberdade.

- PALAVRAS-CHAVE: Kant, Eric Weil, sentido, necessidade, contingência.

Eric Weil trata da questão do sentido em Kant no segundo texto de Problèmes kantiens (1990, p. 57-107), dedicado à Kritik der Urteilskraft de Kant. Segundo Weil, nas duas primeiras Críticas, a unidade do mundo não era objetivamente necessária para Kant, ou melhor, a unidade do mundo era apenas uma ideia, necessária somente como orientação subjetiva para a pesquisa (1990, p. 61). O problema é que tanto a faculdade do entendimento (Verstand) como a da razão (Vernunft) foram insuficientes para revelar a unidade entre os dois mundos: o mundo da natureza e o mundo da liberdade. Por isso, para poder pensar a possibilidade da unidade da natureza com a liberdade, Kant sentiu a necessidade de criar uma nova faculdade, denominada Urteilskraft, traduzida por Weil como judiciaire (judiciária) (1990, p. 8).

Com efeito, mesmo existindo um precipício entre a liberdade e a natureza, a liberdade deve (soll) exercer uma influência sobre a natureza, a qual

1 Doutor em Filosofia e professor adjunto do Instituto de Cultura e Arte da Universidade Federal do Ceará. Artigo recebido em 10/2009 e aprovado em 12/2009. 
deve (muss) se adequar aprioristicamente com o fim estabelecido pela liberdade. Para Weil, o fato de Kant usar o deve (soll) no sentido de obrigação moral, e não de necessidade lógica ou natural (muss), mostra que se trata aqui de um interesse da razão moral. É interesse da razão moral (Vernunft) que a natureza seja pensada em sua unidade e que, consequentemente, exista uma passagem entre as duas maneiras de pensar: prática e teórica (1990, p. 66-7).

Mas não basta proclamar a necessidade metafísica da razão. É preciso que esta seja, também, uma possibilidade real. A unidade do mundo deve ser um fato; porém, sendo um fato, passa a ser fortuita, não-necessária, conquanto é próprio de todo fato ser contingente. Se a unidade do mundo é um fato, o sentido dessa unidade passa a ser claramente insensato.

Essa contingência insensata do sentido, entretanto, mostra, paradoxalmente, a estrutura coerente da natureza. Em poucas palavras, o insensato revela o sensato. Mais precisamente, a existência do insensato ou do contingente revela a necessidade de uma estrutura sensata no mundo, pois é óbvio que o contingente, por si mesmo, pode tanto existir como não existir. Desse modo, a contingência de um sentido cosmológico universal mostra a necessidade da ideia de um cosmos previamente estruturado, sem a qual o homem não teria como pensar o sentido como fato contingente e necessário no mundo (Weil, 1990, p. 68-9).

\section{A finalidade objetiva da natureza}

Segundo F. Marty, pode-se desenvolver a questão do sentido em Kant em duas etapas: uma que destaca as chamadas "estruturas concretas" capazes de receber sentido, e uma outra eminentemente antropológica, fundamentada na capacidade natural do homem de ser "doador de sentido" (1984, p. 342). Ora, como as "estruturas concretas" de sentido são estabelecidas por Kant na Kritik der Urteilskraft mediante o conceito de finalidade, infere-se que a questão do sentido é intrinsecamente unida ao próprio conceito de finalidade.

As principais "estruturas concretas" de finalidade encontram-se na universalidade do julgamento estético e no próprio ser vivente. Com relação ao julgamento estético, sabemos que o belo agrada ao observador de forma desinteressada. O belo não depende de um interesse particular ou de uma ideia de perfeição superior, é puramente e imediatamente experimentado (Weil, 1990, p. 70). Por isso, o belo é universal. Essa universalidade é possível devido à presença da estrutura real do sentimento desinteressado em todos os indivíduos (Weil, 1990, p. 71; Kant, 1974, p. 220-2, § 38). É o sentimento desinteressado que faz com que todos os indivíduos constatem o be- 
lo, reconhecendo-o como fim em si mesmo: "A beleza de uma forma, natural ou de criação artística, impõe-se para mim e considero perfeitamente como natural a adesão de todo homem a meu julgamento" (Weil, 1990, p. 73). Desse modo, o fato de todos os indivíduos serem naturalmente capazes de reconhecer o belo em si mostra que a natureza dotou cada um com as mesmas faculdades, com a mesma organização interior, em vista de uma mesma finalidade: "é a natureza que torna possível e real a humanidade dos homens" (loc. cit.). Esse conceito de finalidade, contudo, não é, evidentemente, científico, mas essencialmente filosófico.

Tudo isso se torna mais complexo e, ao mesmo tempo, mais claro para a reflexão filosófica quando se analisa o organismo vivente. Enquanto o belo é fim para a natureza ou para o indivíduo naturalmente capaz de aderir ao belo, o ser vivente é fim para si mesmo ou, simplesmente, causa e efeito de si mesmo (Weil, 1990, p. 75). Mesmo fazendo parte da natureza, o ser vivente possui uma finalidade interior, independentemente das leis mecânicas da natureza (Weil, 1990, p. 76). Como esclarece Weil: "Para essa finalidade, somente a judiciária é competente, porquanto o entendimento, nesse domínio, é surdo e cego" (loc. cit.). De fato, conquanto seja possível descrever com a física e a química tudo o que contém o vivente, é impossível explicar o que é o vivente sem "a linguagem dos fins, linguagem desconhecida à ciência puramente causalista" (loc. cit.).

É verdade que o desprezo do conceito de finalidade nos meios científicos não é somente culpa da cegueira dos cientistas. A finalidade objetiva greco-antiga e não-intencional foi totalmente transformada pelo voluntarismo teológico. Para o criacionismo judeu-cristão-islâmico, o mundo tem sentido porque foi Deus quem o criou e tudo o que nele existe (Weil, 1999, p. 91). Se o melão é destinado a ser comido pela família, é porque Deus criou o melão com essa intenção (Weil, 1999, p. 95). Com isso, é justificável que o cientista, diante dessa finalidade teológica claramente ingênua, terminasse por desprezar toda teleologia objetiva no mundo e passasse a defender somente a lei da causalidade.

Mas o voluntarismo teológico justifica apenas o abandono da finalidade intencional, não a finalidade objetiva não-intencional da natureza. O problema foi que o cientista jogou a água suja da bacia junto com o bebê, não percebendo que o conceito de finalidade objetiva é imanente ao próprio conceito de causalidade. Com efeito, segundo a interpretação aristotélica de Weil, é a finalidade interna que distingue o não-vivente do vivente. $\mathrm{O}$ biólogo deveria saber, por exemplo, que o órgão, como parte de um organismo, só pode ser compreendido plenamente em relação ao todo do organismo. Se o órgão não fosse compreendido com essa finalidade interna, isto é, como parte de um todo vivente, não seria mais que uma massa material do 
chamado mundo inorgânico, desaparecendo a distinção básica entre o vivente e o não-vivente (Weil, 1999, p. 95).

É preciso incluir tanto a causalidade mecânica como a causalidade final na compreensão da vida natural. Para isso, é importante manter a distinção kantiana entre conhecer (Verstand) e pensar (Vernunft). Com base nessa distinção, é perfeitamente possível pensar a causalidade mecânica como causa explicativa (Verstand) e o conceito de finalidade como causa compreensiva (Vernunft) do ser vivente.

\section{O homem como fim moral da natureza}

Primeiramente, é preciso dizer que a compreensão do ser vivente finito é pensada por Kant com base no infinito ou em um intelecto arquétipo. Essa exigência absoluta de um intelecto infinito tem, porém, sua origem na finitude (Weil, 1990, p. 79). Daí, então, a questão principal posta por Kant em toda a Kritik der Urteilskraft: "como compreender que o compreensível e a compreensão sejam todos os dois fatos e, assim, em última análise, insensatos?" (Weil, 1990, p. 80). Dito de outro modo, se a finalidade e o próprio infinito, enquando pensado por um ser finito, são contingentes e insensatos, de que modo se poderão estabelecer o sentido e a finalidade objetiva do mundo? Afinal de contas, qual é realmente o motivo pelo qual existe o mundo?

Para o Kant de Weil, o sentido do mundo é dado pelo homem moral. Mais claramente, o mundo deve ter um sentido; sentido esse que só é descoberto pelo próprio homem livre e moral, capaz de perguntar pela finalidade da natureza. É preciso distinguir o homem como fim último natural (letzter Zweck) e o homem como fim útimo moral (Endzweck) da natureza. Enquanto fim último natural (letzter Zweck), o homem é o mestre natural da natureza, e, enquanto fim último moral (Endzweck), o homem é o animal que pergunta pela finalidade moral da natureza. Desse modo, enquanto Endzweck, o homem é realmente o fim último da natureza, haja vista que a natureza não conhece por si mesma um incondicionado que possa determinar-lhe o sentido teleológico (Weil, 1990, p. 82-3).

Mas será que com isso a teleologia do sujeito moral, única capaz de compreender o sentido da natureza, suplanta a teleologia natural? De maneira nenhuma, já que a função da teleologia moral não é determinar um sentido metafísico-transcendental para a natureza, mas fundar uma teleologia natural que possa tornar o mundo compreensível em sua totalidade (Weil, 1990, p. 83). Essa questão é difícil de ser compreendida e expressa: de um lado, o homem livre ou sujeito moral é o responsável último pelo sentido da natureza; de outro, o homem só é humano na natureza (Weil, 1990, 
p. 84). ${ }^{2}$ Na verdade, a dialética entre o homem livre e a natureza é no mínimo desconcertante, porque é uma dialética que se constitui com base em um princípio dado, pela própria dialética, como não-dialético. Mais precisamente, a unidade do mundo como fato de sentido é compreendida pelo homem livre ou moral com base na ideia de um mundo previamente estruturado. Usando a surpreendente analogia kantiana entre o verme e o corpo e o sonho e o sono (Kant, 1974, § 67, p. 328-9; Philonenko, 1998, p. 41), podese dizer que, assim como o verme só existe no corpo e o sonho no sono, o homem livre ou moral só existe no mundo. Ademais, a própria natureza conduz o homem à moral, civilizando-o, incitando-o ao progresso, preparandoo para que possa ser fim último (Endzweck) (Weil, 1990, p. 84). Somente aquele que a natureza civilizou pode transcendê-la e, assim, refletir sobre a sentido da existência e do mundo.

Mas, se a teleologia moral permanece incapaz de descobrir o sentido último da natureza, visto que, na verdade, é o mecanismo natural que conduz o homem à moral, com que direito, então, a teleologia moral transcende a natureza pensando-a em sua totalidade? Ora, o direito só pode vir do próprio ser moral e razoável, e, sobretudo, livre. A pressuposição de um mundo sensato supõe a ideia de liberdade, a qual é a única ideia de razão que é ideia de fato, posta por Kant entre as Scibilia, isto é, entre as coisas que se podem saber, e não entre as opinabilia, ou entre as mere credibilia. ${ }^{3}$

"A liberdade se prova na ação" (Weil, 1990, p. 89). Isto significa que o sentido do mundo não se encontra em uma realidade transcendental, suprassensível, mas sim na atitude do homem agente: "Sou eu que apreendo, na conversão à liberdade razoável, na apreensão de meu próprio fundo, a possibilidade de dar um sentido à minha existência e, por conseguinte, àquela do mundo" (Weil, 1990, p. 91). O mundo só terá um sentido na medida em que "o homem se estabelece, na sua ação e por sua decisão, como

2 Para Philonenko, essa posição de Weil inverte o pensamento de Kant, conduzindo-o a uma ontologia pré-crítica (1997, p. 208). Daí, então, a dura conclusão de Philonenko a respeito de Problèmes kantiens: "Esse livro é belo, mas dogmático" (1997, p. 208, nota 63). Sobre isso, ver M. Perine (1987, p. 80, nota 33). Em nossa opinião, Philonenko desconsidera que o sentido encontrado pelo homem na natureza é, para Weil, uma ideia, entendida como fato da razão, e pensada pelo indivíduo finito. Ora, como o fato é sempre contingente, é óbvio que não existe nenhum risco de uma ontologização pré-crítica ou de uma dogmatização na leitura weiliana de Kant.

3 Kant afirma que as coisas conhecidas são de três espécies: coisas da opinião (opinabile), coisas que se podem saber de fato (scibile) e coisas de fé (mere credibile). Os objetos cuja objetividade de seus conceitos pode ser provada são coisas de fato. E, entre as coisas de fato, encontra-se a ideia de liberdade, cuja realidade pode ser demonstrada mediante leis práticas da razão pura, em conformidade com ações efetivas, ou seja, através da experiência. É a única entre todas as ideias da razão (Vernunft) cujo objeto é uma coisa de fato, por isso, deve ser posta entre as coisas que se podem saber, isto é, entre as Scibilia (Kant, 1974, p. 433-5, § 91; Weil, 1990, p. 89). 
sentido, tornando sensata sua própria vida" (Weil, 1990, p. 91-2). Desse modo, o sentido do mundo constitui a própria manifestação da liberdade humana no mundo, mas de uma liberdade originada de um ser finito que superou toda condição a partir da própria condição natural, haja vista que foi a própria natureza que o preparou para essa superação. Com isso, natureza e liberdade são indissoluvelmente ligadas (Weil, 1990, p. 94).

\section{Três condições para pensar-se o sentido}

Resumindo tudo o que foi dito e seguindo a análise de F. Marty, podemos compreender a questão do sentido em Kant com base em três condições. A primeira é a pressuposição da finitude do homem (Marty, 1984, p. 343). Se o homem conhecesse todos os segredos do mundo, não poderia escolher e dar sentido às coisas do mundo. Como diz Weil, "é sua ignorância no nível dos fatos que, sobre o plano da prática, o torna mestre de sentido" (Weil, 1990, p. 97). Como o homem finito pode dar sentido? Para isso, ele precisaria ser ao mesmo tempo universal. Por isso, somente o homem universalizado pela moral pode dar sentido ao fato finito. Mas a partir de qual momento o indivíduo deixa de ser apenas um dado da natureza para tornar-se um sujeito moral e agente? É nesse ponto que encontramos uma das principais "descobertas" kantianas de Weil. Trata-se da definição do homem como ser "finito e razoável". Segundo Weil, os intérpretes pós, anti e neokantianos não têm dado a devida atenção a essa concepção antropológica de Kant, a qual representa realmente "o centro e o núcleo da reflexão kantiana" (Weil, 1990, p. 111). Dizer que o homem é "razoável e finito" significa dizer que o homem, apesar de finito e, por conseguinte, sujeito às paixões e à violência natural da contingência, é, também, capaz de pensar a "totalidade estruturada do mundo" (Weil, 1990, p. 111-2). Ao pensar o mundo como totalidade, o homem finito torna-se, perfeitamente, capaz de compreender o sentido ou a finalidade das partes dentro do Todo razoável. Percebe-se, com isso, a diferença da leitura do finito kantiano de Weil em relação à interpretação do finito kantiano em Heidegger. Com efeito, enquanto Heidegger (1965) fundamenta em seu Kantbuch a ideia de finito na Estética e na Analítica da Kritik der reinen Vernunft, ignorando, assim, completamente a Dialética desta e as duas últimas Críticas, Weil fundamenta a ideia de finito na Kritik der Urteilskraft, consciente de que a terceira Crítica contém, de certa forma, a unidade de todo sistema kantiano. ${ }^{4}$ Para Weil, a terceira Crítica possibilita a Kant "pensar não somente o funda-

4 Sobre a diferença das leituras weiliana e heideggeriana de Kant, ver G. Kirscher (1999, p. 259-80). 
mento necessário de todo julgamento científico ou moral, mas a realidade que esses julgamentos apreendem" (Weil, 1990, p. 8).

A segunda condição para a questão do sentido, estreitamente coligada com a primeira, mostra a relação do homem finito e moral com a estrutura sensata da natureza (Marty, 1984, p. 343). Para Weil, a estrutura sensata do mundo é um postulado não-dogmático extremamente claro: "Se o mundo não fosse estruturado, não poderíamos falar seriamente. Em um mundo de entropia total, não faríamos filosofia, direito ou qualquer outra coisa" (Weil, 1982, p. 50). Isso não significa, evidentemente, que conheçamos a estrutura do mundo: "Podemos pressupor que o mundo é estruturado, mas não podemos nunca dizer de uma vez por todas qual é a estrutura" (loc. cit.). Por isso, o discurso filosófico deve estar sempre aberto ao sentido da totalidade do mundo.

A terceira condição para a "questão do sentido" elencada por F. Marty (1984, p. 344) é que, somente assumindo sua finitude e sua contingência em um mundo previamente organizado, o homem poderá exercer sua liberdade e optar livremente pelo discurso filosófico razoável, não obstante a aparente vitória da violência no mundo. É pensando o mundo como estruturado que o homem terá condições de pensar o sentido do mundo. Na verdade, existe uma íntima relação entre a razão humana e a estrutura do mundo. Como afirma Weil, a razão existe como fato mítico-estrutural no mundo antes mesmo de ser pensada pelo filósofo: "ele não começa o pensamento; o pensamento pré-existe e o precede, insuficiente, primitivo, mítico, mas sempre anterior à sua empresa pessoal, condição restringente, mas fundante" (1982, p. 32). É verdade que a razão enquanto fato no mundo é, também, contingente. O homem que opta pela razão, porém, opta pelo sentido e contra a violência, sabendo que no fundo a estrutura da razão constitui a mesma estrutura sensata do mundo. Se existe filosofia, é porque existe a razão, e, se existe a razão, é porque o mundo é estruturado, ou seja, é passível de ser compreendido como sensato pelo homem finito e razoável. É o homem moral agente que concretiza o sentido no mundo. Como este sentido é imanente à própria natureza, conclui-se, então, que existe uma perfeita simbiose entre o homem moral e a estrutura sensata da natureza.

\section{Considerações finais}

O problema foi que Kant não conseguiu encontrar uma linguagem apropriada para expressar o sentido como fato, ou melhor, uma linguagem que permitisse passar "de uma filosofia do ser [...] a uma filosofia do sentido", ou, ainda, uma linguagem que pudesse "exprimir que fato e sentido são indissoluvelmente unidos" (Weil, 1990, p. 105). Mesmo não conseguin- 
do encontrar uma linguagem apropriada a seu pensamento, porém, Kant conseguiu, objetivamente falando, fechar o abismo que separava fato e sentido (Weil, 1990, p. 107).

Segundo a interpretação weiliana, a questão do Sentido não pode ser posta nem resolvida por uma filosofia do Ser. Como é fácil perceber, estamos aqui diante de um ponto crucial na história da filosofia. Normalmente, o discurso filosófico tende a considerar o Ser como fundamento e sentido último do discurso. Por isso, é difícil imaginar que a filosofia do Ser não seja capaz de pensar a questão do sentido. Ora, o sentido, como fato, não pode ser necessário (Weil, 1990, p. 104). Se o sentido fosse pensado, por exemplo, com base em Deus, ele seria dogmático, por conseguinte, não existiria possibilidade de o homem pensar livremente o sentido de sua existência. Por isso, a linguagem do Ser não é a linguagem do sentido.

É para preservar a liberdade do homem como "doador de sentido" que Kant mantém a contingência do sentido no mundo. Aliás, é interessante observar que a própria Judiciária é contingente, ao contrário da Razão teórica e da Razão prática. No caso, por exemplo, da razão prática moral, não existe possibilidade de contingência: "a lei moral não pode ser outra do que é" (Weil, 1990, p. 105). Já o fato do sentido pode, como tal, tanto ser fortuito como necessário. É por isso que a linguagem ontológica do Ser é insuficiente para falar do sentido, pois não consegue pensar o sentido como fato contingente e necessário ao mesmo tempo.

Para Weil, o grande mérito de Kant foi ter mostrado que "toda filosofia do Ser conduz necessariamente ao naufrágio, porque impede de se chegar ao sentido e, em particular, ao sentido que sua própria questão pode ter para quem a põe" (Weil, 1990, p. 107). A questão do sentido não se encontra em um Ser transcendente, mas na própria natureza estruturada e sensata. Por isso, observa Weil, ao fundamentar o fato do sentido em um mundo previamente estruturado, Kant aproximou, sem disso ter plena consciência, a cosmologia moderna da cosmologia grega (loc. cit.). Trata-se de um retorno crítico, com base no pensamento moderno, à ideia de um cosmo coerente e sensato, necessário para a formação do homem moral e razoável. O homem moral é capaz de dar sentido porque o recebe da natureza objetivamente estruturada: "O bárbaro não se torna filósofo; aquele que a natureza civilizou é o único capaz de transcender todo dado em uma reflexão consciente sobre o sentido de sua existência e o do mundo" (Weil, 1990, p. 85).

COSTESKI, Evanildo. The issue of sense in Kant according to Eric Weil. Trans/Form/ Ação, São Paulo, v.32(2), 2009, p.91-99. 
- ABSTRACT: This article is intended to show that, according to Weil, Kant discovered the problem of sense. Weil, however, believed that Kant failed to final an appropriate language to adress the problem he discovered. Kant's language was still ontological. Despite this, Weil thought Kant succeeded in closing the gap between nature and liberty in the third Critique.

- KEYWORDS: Kant, Eric Weil, sense, necessity, contingency.

\section{Referências bibliográficas}

HEIDEGGER, Martin. Kant und das Problem der Metaphysik. Frankfurt am Main: Vittorio Klostermann, 1965.

KANT, Immanuel. Kritik der Urteilskraft. Frankfurt am Main: Suhrkamp, 1974.

KIRSCHER, Gilbert. Eric Weil ou la raison de la philosophie. Villeneuve D'Ascq: Presses Universitaires du Septentrion, 1999.

MARTY, François. Le surgissement de la question du sens chez Kant, selon Eric Weil. Actualité d'Eric Weil: Actes du Colloque International, Chantilly, 21-22 de maio de 1982. Paris: Beauchesne, 1984, p. 341-7.

PERINE, Marcelo. Filosofia e violência. Sentido e intenção da filosofia de Eric Weil. São Paulo: Loyola, 1987.

PHILONENKO, Alexis. L'œuvre de Kant. Paris: Vrin, v. 2. 1997. La théorie kantienne de l'histoire. Paris: Vrin, 1998.

WEIL, Eric. Philosophie et réalité. Philosophie et réalité. Derniers essais et conférences. Paris: Beauchesne, 1982, p. 23-57.

Problèmes kantiens. Paris: Vrin, 1990.

Essais sur la nature, l'histoire et la politique. Villeneuve d'Ascq: Presses Universitaires du Septentrion, 1999. 